\title{
Combination therapy with bosentan and sildenafil in idiopathic pulmonary arterial hypertension
}

\author{
M.M. Hoeper*, C. Faulenbach*, H. Golpon*, J. Winkler*, T. Welte*, J. Niedermeyer*
}

Combination therapy with bosentan and sildenafil in idiopathic pulmonary arterial hypertension. M.M. Hoeper, C. Faulenbach, H. Golpon, J. Winkler, T. Welte, J. Niedermeyer. (C) ERS Journals Ltd 2004.

ABSTRACT: It has been proposed that targeted treatments should be combined for patients with idiopathic pulmonary arterial hypertension (IPAH) responding insufficiently to monotherapy.

This study followed the clinical course of nine patients with severe IPAH, in whom the endothelin receptor antagonist bosentan caused transient clinical improvement, eventually followed by a decline in exercise tolerance, who received adjunct treatment with the phospodiesterase-5-inhibitor sildenafil. Measurements included the 6-min walk distance (6MWD) and cardiopulmonary exercise testing (CPET).

The 6MWD at baseline was $346 \pm 66 \mathrm{~m}$ and improved to $403 \pm 80 \mathrm{~m} 3$ months after introduction of bosentan treatment. However, this effect was not sustained and, after an interval of $11 \pm 5$ months, the walk distance had declined to $277 \pm 80 \mathrm{~m}$. At this point, sildenafil was added to bosentan. Three months later, the 6MWD had increased to $392 \pm 61 \mathrm{~m}$ and the patients remained stable throughout the median follow-up of 9 months (range 6-12). Measurement of the maximum oxygen uptake during CPET confirmed these results. The combination of bosentan and sildenafil was well tolerated by all patients.

These preliminary data suggest that combining bosentan and sildenafil may be safe and effective in patients with idiopathic pulmonary arterial hypertension.

Eur Respir J 2004; 24: 1007-1010.
*Dept of Respiratory Medicine, Hannover Medical School, Hannover, and ${ }^{\#}$ Dept of Cardiopulmonary Medicine, University of Leipzig, Leipzig, Germany.

Correspondence: M.M. Hoeper

Hannover Medical School

Dept of Respiratory Medicine

Carl-Neuberg-Str. 1

30625 Hannover

Germany

Fax: 495115328536

E-mail: hoeper.marius@mh-hannover.de

Keywords: Bosentan

endothelin receptor antagonists

hypertension

phosphodiesterase inhibitors

pulmonary

sildenafil

Received: April 292004

Accepted after revision: July 72004
Idiopathic pulmonary arterial hypertension (IPAH), formerly called primary pulmonary hypertension (PPH), is a disease of unknown aetiology, characterised by progressive pulmonary vascular remodelling, ultimately leading to right heart failure and death [1,2]. Without targeted treatment, IPAH carries a grave prognosis, with a median survival of 2.8 yrs after diagnosis [3].

In the last few years, a number of novel treatments for this devastating disease have been developed and are now in use. Intravenous epoprostenol has been shown in several studies to improve haemodynamics, exercise tolerance and survival [4-6]. To circumvent the risks, inconveniences and costs associated with continuous intravenous epoprostenol, stable prostacyclin analogues have been introduced that can be administered orally, subcutaneously or by inhalation [7]. In patients with IPAH, all these substances have been shown to improve exercise tolerance and haemodynamics in relatively short-term clinical studies [8-10], but the effects on long-term survival have not been thoroughly investigated.

Besides prostaglandins, novel substances with different mechanisms of action have been introduced in recent years. The dual endothelin receptor antagonist bosentan has been approved throughout the western world for treatment of pulmonary arterial hypertension (PAH) [11]. In addition, several case series and one small controlled study have suggested that phosphodiesterase-5-inhibitors, such as sildenafil, may have beneficial effects in PAH [12, 13].

Despite the fact that all of these substances have positive effects in IPAH, they do not provide a cure and, in many patients, the disease will eventually progress. The optimal management for patients who exhibit clinical deterioration despite targeted treatment is unclear. The introduction of intravenous epoprostenol is an option for patients in whom treatment with endothelin receptor antagonists, nonintravenous prostanoids or sildenafil fails. Another option is combination treatment [14]. A few uncontrolled clinical studies have suggested that combinations of aerosolised iloprost and sildenafil, as well as aerosolised iloprost and bosentan, are safe and effective in selected patients with progressive disease despite prostanoid treatment $[15,16]$. Combining bosentan and sildenafil may also be an attractive choice, since both substances are orally available, act via different mechanisms and are usually well tolerated. This paper describes the clinical course of nine patients with severe and progressive IPAH who were treated with a combination of bosentan and sildenafil.

\section{Patients and methods}

Between January 2002 and December 2003, 58 patients received bosentan for treatment of IPAH at Hannover Medical School (Hannover, Germany). Bosentan was used either as first-line therapy or in addition to a prostanoid (i.e. inhaled iloprost, oral beraprost or intravenous iloprost). Treatment efficacy was monitored primarily by the 6-min walk distance (6MWD) and cardiopulmonary exercise testing (CPET), and was targeted to reach pre-defined goals 
based on prognostically relevant variables: a 6 MWD $>380 \mathrm{~m}$ [6] and a peak oxygen uptake measured during CPET $>10.4 \mathrm{~mL} \cdot \mathrm{min}^{-1} \cdot \mathrm{kg}^{-1}$ [17]. Patients who did not reach these goals on two consecutive visits were offered additional treatment with sildenafil. There was no formal study protocol. All patients were informed about the fact that this approach was investigational, that long-term data on safety and efficacy of sildenafil in PAH were not available, that there were no experiences with the combination of bosentan and sildenafil, and about the alternative option to receive intravenous prostacyclin treatment.

\section{Treatments and follow-up}

All patients had an extensive diagnostic work-up to define the aetiology of pulmonary hypertension, including, but not limited to, ventilation-perfusion scanning, computed tomography of the chest, right heart catheterisation and pulmonary angiography, when indicated. Bosentan was considered first-line treatment for patients newly diagnosed with IPAH. After initiation of bosentan treatment, the patients were seen in the outpatient clinic in 3-4 monthly intervals. Follow-up examinations included regular 6MWD [18] and CPET [16]. Repeated right heart catheterisations were not part of the routine follow-up programme.

Bosentan treatment was started at a dose of $2 \times 62.5 \mathrm{mg}$ and the dose was increased to $2 \times 125 \mathrm{mg}$ after 4 weeks in all patients. Liver enzymes were monitored every 4 weeks. The dose of bosentan was not changed throughout the observation period.

Sildenafil was started at a dose of $3 \times 25 \mathrm{mg}$ (or $4 \times 25 \mathrm{mg}$ ) and was increased after $4-12$ weeks to $3 \times 50 \mathrm{mg}$ when the response to the initial dose was not sufficient (i.e. when the treatment goals as defined above where not reached).

\section{Analysis}

All values are given as mean \pm SD. Two baselines were set: the first one before bosentan was started and the second one before sildenafil was started. The treatment effects after 3 months were compared with the baseline values using paired ttests (two-sided). A p-value $<0.05$ was considered statistically significant.

\section{Results}

Within the observation period, 2002-2003, nine out of 58 patients with IPAH, initially treated with bosentan or a combination of bosentan and a prostanoid, fulfilled the predefined criteria of clinical worsening as defined above. These patients suffered from severe and progressive pulmonary hypertension, and were in New York Heart Association (NYHA) functional class III or IV before treatment was started. All patients were nonresponders to acute vasodilator challenge. The baseline characteristics and haemodynamics of these patients are shown in table 1 .

\section{Functional classification}

At baseline, eight patients were functional class (FC) III and one patient was FC IV. Three months after bosentan was started, two patients had improved to FC II and the patient who formerly was FC IV had improved to FC III. However, after a follow-up of $11 \pm 5$ months, deterioration occurred in all patients and, before sildenafil was added to bosentan, seven patients were FC III and two patients were FC IV. After 3 months of treatment with bosentan and sildenafil, six patients were FC III and three patients were FC II. During the follow-up period of 6-12 months, two further patients improved from FC III to FC II (table 2).

Table 1.-Patients' baseline characteristics and haemodynamics

\begin{tabular}{lc}
\hline Age yrs & $39 \pm 9$ \\
Sex female/male & $7 / 2$ \\
NYHA class III/IV & $8 / 1$ \\
6MWD m & $337 \pm 73$ \\
Mean right atrial pressure mmHg & $9 \pm 5$ \\
Mean pulmonary arterial pressure $\mathrm{mmHg}$ & $62 \pm 12$ \\
Cardiac output $\mathrm{L} \cdot \mathrm{min}^{-1}$ & $3.1 \pm 0.7$ \\
Cardiac index $\mathrm{L} \cdot \mathrm{min}^{-1} \cdot \mathrm{m}^{-2}$ & $1.6 \pm 0.3$ \\
Pulmonary vascular resistance dynes $\cdot \mathrm{s} \cdot \mathrm{cm}^{-5}$ & $1549 \pm 440$ \\
Mixed venous oxygen saturation $\%$ & $53 \pm 10$ \\
\hline
\end{tabular}

NYHA: New York Heart Association; 6MWD: 6-min walk distance. $1 \mathrm{mmHg}=0.133 \mathrm{kPa}$.

Table 2. - Individual functional classes (New York Heart Association (NYHA)) and 6-min walk distance (6-MWD)

\begin{tabular}{|c|c|c|c|c|c|c|c|c|c|c|}
\hline \multirow[t]{2}{*}{$\begin{array}{l}\text { Patient } \\
\text { no. }\end{array}$} & \multicolumn{2}{|c|}{$\begin{array}{c}\text { Baseline } 1 \\
\text { before bosentan }\end{array}$} & \multicolumn{2}{|c|}{$\begin{array}{l}3 \text { months after } \\
\text { introduction of bosentan }\end{array}$} & \multicolumn{2}{|c|}{$\begin{array}{c}\text { Baseline } 2 \\
\text { before sildenafil }\end{array}$} & \multicolumn{2}{|c|}{$\begin{array}{l}3 \text { months after } \\
\text { addition of sildenafil }\end{array}$} & \multicolumn{2}{|c|}{$\begin{array}{l}6-12 \text { months after } \\
\text { addition of sildenafil }\end{array}$} \\
\hline & NYHA & 6-MWD & NYHA & 6-MWD & NYHA & 6-MWD & NYHA & 6-MWD & NYHA & 6-MWD \\
\hline 1 & III & 393 & II & 478 & III & 297 & III & 363 & III & 373 \\
\hline $2^{\#}$ & III & 336 & III & 428 & III & 226 & III & 354 & II & 410 \\
\hline 3 & III & 367 & III & 406 & III & 354 & II & 450 & II & 462 \\
\hline 4 & III & 337 & III & 403 & IV & 132 & II & 414 & II & 382 \\
\hline 5 & III & 420 & II & 497 & III & 371 & III & 421 & II & 481 \\
\hline 6 & III & 328 & III & 406 & III & 353 & III & 425 & III & 425 \\
\hline $7^{\bullet}$ & III & 330 & III & 343 & III & 303 & III & 335 & III & 345 \\
\hline 8 & IV & 198 & III & 232 & III & 252 & III & 290 & III & 328 \\
\hline 9 & III & 406 & III & 434 & IV & 203 & II & 480 & II & 450 \\
\hline
\end{tabular}

${ }^{\#}$ : receiving inhaled iloprost since 15 months before bosentan was started and iloprost was continued throughout the observation period; ${ }^{\top}$ : bosentan replaced continuous intravenous iloprost that had been given for 2 yrs but had to be withdrawn after several episodes of life-threatening line sepsis, sildenafil was added 11 months after introduction of bosentan. 


\section{Six-min walk distance}

As shown in figure 1 and table 2, the 6MWD at baseline was $346 \pm 66 \mathrm{~m}$. After introduction of bosentan treatment, the 6MWD improved by $57 \mathrm{~m}$ to $403 \pm 80 \mathrm{~m}$ ( $\mathrm{p}=0.0003$ ). However, this effect was not sustained and, after an interval of $11 \pm 5$ months, the walk distance had declined to $277 \pm 80 \mathrm{~m}$. At this point, sildenafil was added to bosentan. Three months later, the 6MWD had increased to $392 \pm 61 \mathrm{~m}(\mathrm{p}=0.007)$ and the patients remained stable throughout the median follow-up of 9 months (range 6-12).

\section{Cardiopulmonary exercise testing}

Complete sets of data from CPET at all time points (baseline 1, three months after introduction of bosentan, baseline 2 and 3 months after the addition of sildenafil) were available from six patients. In these patients, the peak oxygen uptake $\left(V^{\prime} \mathrm{O}_{2}\right.$,peak $)$ was $9.9 \pm 1.9 \mathrm{~mL} \cdot \mathrm{min}^{-1} \cdot \mathrm{kg}^{-1}$ at baseline and increased to $12.3 \pm 1.9 \mathrm{~mL} \cdot \mathrm{min}^{-1} \cdot \mathrm{kg}^{-1} 3$ months after introduction of bosentan $(\mathrm{p}=0.02)$. As with the walking distance, this effect was not sustained and, before introduction of sildenafil, $V^{\prime} \mathrm{O}_{2}$, peak had decreased to $10.4 \pm 2.3 \mathrm{~mL} \cdot \mathrm{min}^{-1} \cdot \mathrm{kg}^{-1}$. Three months after sildenafil was added to bosentan, $V^{\prime} \mathrm{O}_{2}$, peak had increased to $13.8 \pm 1.5 \mathrm{~mL} \cdot \mathrm{min}^{-1} \cdot \mathrm{kg}^{-1}(\mathrm{p}=0.006)$.

\section{Side-effects}

None of the patients in this case series died or experienced any drug-related serious adverse event. There were no abnormalities of liver enzymes before or after the introduction of bosentan, or after addition of sildenafil. All patients reported minor headache and flushing when sildenafil was added to bosentan, but these problems resolved within a few days without dose adjustments. The same was true with heartburn, reported by one patient after sildenafil was started. No patient described symptoms attributable to hypotension and there were no episodes of syncope during the observation period.

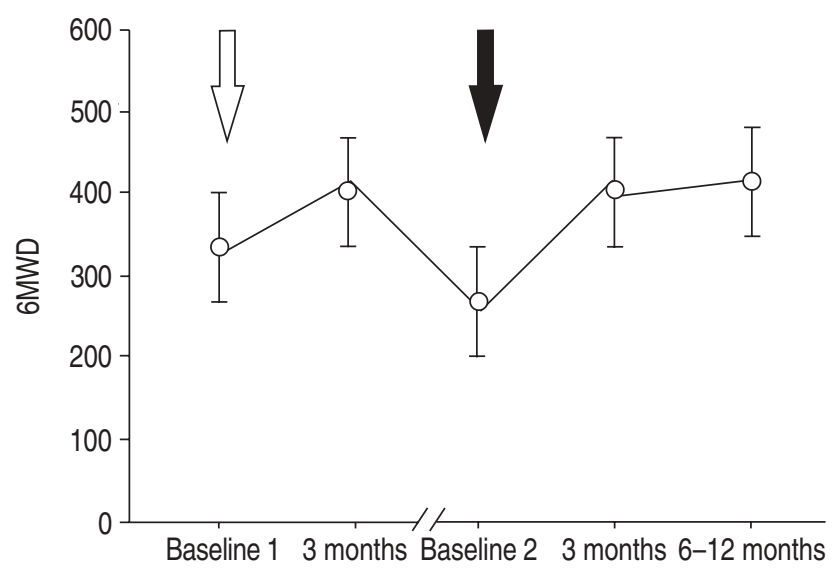

Fig. 1.-Six-min walk distance (6MWD) of nine patients with idiopathic pulmonary arterial hypertension at baseline 1 (before treatment with bosentan), 3 months after introduction of bosentan, baseline 2 (11 \pm 5 months later before addition of sildenafil), 3 months later and 6-12 months later. Open arrow: bosentan started; closed arrow sildenafil started.

\section{Discussion}

This case series may serve as a pilot trial showing that combining bosentan and sildenafil might be feasible in patients with IPAH. This combination was well tolerated by all patients and proved to be highly efficient. Of note, this patient population consisted of a "negatively" selected subgroup of young patients with very severe and rapidly progressive IPAH. Before targeted treatment was initiated, all patients were in functional class NYHA III or IV, and haemodynamic assessment confirmed the presence of advanced pulmonary hypertension with a mean pulmonary artery pressure of $62 \pm 12 \mathrm{mmHg}$, a cardiac index of $1.6 \pm 0.3 \mathrm{~L} \cdot \mathrm{min}^{-1} \cdot \mathrm{m}^{-2}$ and a pulmonary vascular resistance of $1,549 \pm 440$ dynes $\cdot \mathrm{s} \cdot \mathrm{cm}^{-5}$. In accordance with current recommendations [7, 14], bosentan was started as first-line treatment, resulting in clinical improvement and increased exercise tolerance as determined by 6MWD and CPET. However, in contrast to the majority of patients receiving treatment with bosentan, this effect was not sustained. After an average period of close to $1 \mathrm{yr}$, the patients showed clinical deterioration and a marked decline in 6MWD, as well as in $V^{\prime} \mathrm{O}_{2}$,peak. It is the unfortunate clinical reality that, even with the novel targeted treatments available for PAH, a certain proportion of patients are going to deteriorate after initial improvement. Those patients are very likely to die from their underlying disease and they do require aggressive treatment. The most recent world conference on pulmonary hypertension recommended that prostacyclin treatment or, alternatively, combination treatment should be initiated in patients not responding sufficiently to treatment with endothelin receptor antagonists or nonintravenous prostanoids [14]. Since bosentan clearly had a beneficial effect in all of the patients in the current study, the authors decided to initiate combination treatment, reserving intravenous prostacyclin for treatment failures. For reasons discussed below, sildenafil was chosen as an add-on treatment. The combination of bosentan and sildenafil was surprisingly well tolerated by all patients and resulted in marked clinical improvement. The pre-defined treatment goals (6MWD $>380 \mathrm{~m}$ and $V^{\prime} \mathrm{O}_{2}$, peak $>10.4 \mathrm{~mL} \cdot \mathrm{min}^{-1} \cdot \mathrm{kg}^{-1}$ ) were reached in six out of nine patients. The remaining patients were judged as sufficiently stable and showed a tendency towards further improvement during follow-up, so that introduction of intravenous prostacyclin was not deemed immediately necessary. It is noteworthy that none of the patients died during the observation period of $21 \pm 3$ months, even though the expected 1 -yr and 2-yr survival probabilities of these patients based on their baseline haemodynamics according to the formula of the National Institutes of Health were 0.64 and 0.51 , respectively [3].

Obviously, this observational report has several inherent limitations: there was no control group, the patient population was small and the overall observation time was rather limited. In addition, treatment with bosentan and sildenafil was not part of a formal study protocol, and serial right heart catheter examinations were not performed and, therefore, haemodynamic follow-up data were not available. Although these data would be of value, it is the authors' practice to base most therapeutic decisions on the results of patient's self reporting (functional classification), clinical examination, 6MWT and CPET, and to reserve right heart catheterisation for open questions or for certain therapeutic decisions, such as listing for highly urgent lung transplantation.

Bosentan and sildenafil were combined rather than bosentan and a prostanoid for several reasons: at the time when combination treatment was initiated in the patients, bosentan was the only drug approved for treatment of IPAH 
in Germany (sildenafil, beraprost and treprostinil have not been approved in Germany, and aerosolised iloprost was officially introduced in January 2004); beraprost or treprostinil were not considered as first choices for combination treatment because the former drug has not been shown to exhibit long-term clinical efficacy [19] and the latter one commonly causes substantial infusion site pain [10]; compared to inhaled iloprost, sildenafil has the practical advantage of being orally administered rather than requiring six to nine inhalations daily; and in addition, although it has been shown that inhaled iloprost and sildenafil have synergistic effects $[15,20,21]$, it was hypothesised that the combination of substances with different intracellular modes of action might be advantageous in the long run, although comparative studies are required to resolve this issue.

Economical considerations also contributed to the decision to combine bosentan and sildenafil. In Germany, the annual treatment costs for a single patient are $\sim € 45,000$ for bosentan, $€ 70,000$ for inhaled iloprost and $€ 5,000-10,000$ (depending on the dose) for sildenafil. Thus, the annual costs for combining bosentan and sildenafil are $€ 50,000-55,000$, compared to $€ 75,000-80,000$ for inhaled iloprost plus sildenafil and $€ 115,000$ for inhaled iloprost plus bosentan. In comparison, in Germany, the annual treatment costs for intravenous epoprostenol are $€ 230,000$ (at a dose of $25 \mathrm{ng} \cdot \mathrm{kg}^{-1} \cdot \mathrm{min}^{-1}$, which is a typical average dose in patients receiving epoprostenol for $>1 \mathrm{yr}[5,6]$ ) and those for intravenous iloprost are $€ 180,000$ (at a dose of $2 \mathrm{ng} \cdot \mathrm{kg}^{-1} \cdot \mathrm{min}^{-1}$, a typical average dose for intravenous iloprost [16]). Thus, when the clinical situation mandates combination treatment or the introduction of intravenous prostacyclin, the annual savings with the combination bosentan and sildenafil are $>€ 100,000$ for every patient, meaning that the approach in this study resulted in savings of $>€ 1,000,000$ just based on the nine patients described.

Despite these considerations, many open questions remain: it is unknown whether combination treatment is truly more efficient than single treatment (although theoretical reasoning clearly favours combination treatment, switching to sildenafil may have been equally effective as combining bosentan and sildenafil); it is unknown which combination regimens exert favourable long-term results (this will be difficult to answer as the number of potentially useful combinations is exponentially increasing with the introduction of novel treatments for $\mathrm{PAH})$; and finally, so far, the combination of bosentan and sildenafil has only been used in patients with IPAH, and it is unknown whether these observations also apply to other forms of pulmonary hypertension.

In conclusion, the data presented here provide preliminary evidence that the combination of bosentan and sildenafil may be safe and effective in selected patients with idiopathic pulmonary arterial hypertension.

\section{References}

1. Rubin LJ. Primary pulmonary hypertension. $N$ Engl $J$ Med 1997; 336: 111-117.

2. Gaine S. Pulmonary hypertension. JAMA 2000; 284: 31603168 .

3. D'Alonzo GE, Barst RJ, Ayres SM, et al. Survival in patients with primary pulmonary hypertension. Results from a national prospective registry. Ann Intern Med 1991; 115: 343-349.
4. Barst RJ, Rubin LJ, Long WA, et al. A comparison of continuous intravenous epoprostenol (prostacyclin) with conventional therapy for primary pulmonary hypertension. The Primary Pulmonary Hypertension Study Group. N Engl J Med 1996; 334: 296-302.

5. McLaughlin VV, Shillington A, Rich S. Survival in primary pulmonary hypertension: the impact of epoprostenol therapy. Circulation 2002; 106: 1477-1482.

6. Sitbon $\mathrm{O}$, Humbert $\mathrm{M}$, Nunes $\mathrm{H}$, et al. Long-term intravenous epoprostenol infusion in primary pulmonary hypertension. Prognostic factors and survival. $\mathrm{J} \mathrm{Am} \mathrm{Coll}$ Cardiol 2002; 40: 780-788.

7. Hoeper MM, Galie N, Simonneau G, Rubin LJ. New treatments for pulmonary arterial hypertension. Am J Respir Crit Care Med 2002; 165: 1209-1216.

8. Galie N, Humbert M, Vachiery JL, et al. Effects of beraprost sodium, an oral prostacyclin analogue, in patients with pulmonary arterial hypertension: a randomized, doubleblind, placebo-controlled trial. J Am Coll Cardiol 2002; 39: 1496-1502.

9. Olschewski H, Simonneau G, Galie N, et al. Inhaled iloprost for severe pulmonary hypertension. N Engl J Med 2002; 347: 322-329.

10. Simonneau G, Barst RJ, Galie N, et al. Continuous subcutaneous infusion of treprostinil, a prostacyclin analogue, in patients with pulmonary arterial hypertension. A double-blind, randomized, placebo-controlled trial. $\mathrm{Am} \mathrm{J}$ Respir Crit Care Med 2002; 165: 800-804.

11. Rubin LJ, Badesch DB, Barst RJ, et al. Bosentan therapy for pulmonary arterial hypertension. $N$ Engl J Med 2002; 346: 896-903.

12. Michelakis ED, Tymchak W, Noga M, et al. Long-term treatment with oral sildenafil is safe and improves functional capacity and hemodynamics in patients with pulmonary arterial hypertension. Circulation 2003; 20: 20.

13. Sastry BK, Narasimhan C, Reddy NK, Raju BS. Clinical efficacy of sildenafil in primary pulmonary hypertension: a randomized, placebo-controlled, double-blind, crossover study. J Am Coll Cardiol 2004; 43: 1149-1153.

14. Galie N, Seeger W, Naeije R, Simonneau G, Rubin LJ. Comparative analysis of clinical trials and evidence-based treatment algorithm in pulmonary arterial hypertension. J Am Coll Cardiol 2004; 43: S81-S88.

15. Ghofrani HA, Rose F, Schermuly RT, et al. Oral sildenafil as long-term adjunct therapy to inhaled iloprost in severe pulmonary arterial hypertension. J Am Coll Cardiol 2003; 42: $158-164$

16. Hoeper MM, Taha N, Bekjarova A, Gatzke R, Spiekerkoetter E. Bosentan treatment in patients with primary pulmonary hypertension receiving nonparenteral prostanoids. Eur Respir J 2003; 22: 330-334.

17. Wensel R, Opitz C, Anker SD, et al. Assessment of survival in patients with primary pulmonary hypertension: importance of cardiopulmonary exercise testing. Circulation 2002; 106: 319-324.

18. ATS statement: guidelines for the six-minute walk test. $\mathrm{Am}$ J Respir Crit Care Med 2002; 166: 111-117.

19. Barst RJ, McGoon M, McLaughlin V, et al. Beraprost therapy for pulmonary arterial hypertension. J Am Coll Cardiol 2003; 41: 2119-2125.

20. Wilkens H, Guth A, Koenig J, et al. Effect of inhaled iloprost plus oral sildenafil in patients with primary pulmonary hypertension. Circulation 2001; 104: 1218-1222.

21. Ghofrani HA, Wiedemann R, Rose F, et al. Combination therapy with oral sildenafil and inhaled iloprost for severe pulmonary hypertension. Ann Intern Med 2002; 136: 515522. 